\title{
Motivational Strategies, Task Effectiveness and Incidental Acquisition of Second Language Vocabulary
}

\author{
Parviz Ajideh \\ Department of Foreign Languages and Literature, University of Tabriz, Tabriz, Iran \\ Massoud Rahimpour \\ Department of Foreign Languages and Literature, University of Tabriz, Tabriz, Iran; \\ School of Languages and Comparative Cultural Studies, University of Queensland, Australia
}

Davoud Amini

Department of Foreign Languages and Literature, University of Tabriz, Tabriz, Iran

Farahman Farrokhi

Department of Foreign Languages and Literature, University of Tabriz, Tabriz, Iran

\begin{abstract}
Current approaches to $\mathrm{L}_{2}$ motivation view language learning motivation as situated, dynamic and task-dependent (Pawlak, 2012). Despite the widespread recognition of motivation as a crucial variable in $L_{2}$ acquisition, few studies have focused on the effect of motivational involvement of learners in an instructional setting, such as task-based language teaching context, on learning achievements. This study aimed at probing the effect of motivational strategies (Dornyei, 2001b) applied to the pre-task phase of task implementation on short-term and long-term retention and ease of activation of $L_{2}$ vocabulary acquired incidentally as a result of engagement with a reading-while listening task. Multivariate analysis of covariance (MANCOVA) revealed that motivational strategies had an enhancing effect on both retention and ease of activation of $L_{2}$ vocabulary upon the immediate post-test. However, the enhancement was not observed for long-term acquisition since there was a considerable decay of retention and ease of activation upon the delayed post-test. The results confirm the effectiveness of task-specific motivation in improving linguistic achievements. Nevertheless, it is argued that motivational strategies cannot be a single substitution for cognitive strategies.
\end{abstract}

Index Terms - task motivation, motivational strategies, incidental acquisition, second language vocabulary, task-based language teaching

\section{INTRODUCTION}

Learning a second language to higher levels of proficiency requires developing a high level of lexical competence. This development can occur either intentionally, i.e. with explicit intention on the learner's part to learn the words' form and use, or incidentally through exposure to the oral or written text. It is admitted that a large size of vocabulary can develop not through instruction, rather implicitly as a by-product of involvement in meaningful use of language. Taskbased language teaching (TBLT) offers a means to involve learners in primarily meaning-focused activities while taking the advantage of opportunities to focus learners' attention, in an implicit manner, on formal aspects of language including its lexicon (Laufer, 2005). Nevertheless, not all tasks are equally effective in promoting vocabulary acquisition. In fact, classifying tasks in terms of their effectiveness in mental actions involving vocabulary learning has been the major concern of many of studies (Laufer and Hulstijn, 2001; Skehan, 1998; Westholf, 2004).

A preliminary examination of related literature indicates that most of these studies have focused largely on cognitive processes involved in task-induced acquisition (Rahimpour, 1997; Robinson, 2001; Skehan, 1998). The affective and motivational processes have failed to receive the due attention regarding their significant position as determining factors in task performance and the subsequent learning attributable to it (Swain, 2012). Although the Involvement Load Hypothesis (Laufer \& Hulstijn, 2001) defines task-effectiveness in terms of both motivational and cognitive variables involved in the processing of words through tasks, studies carried out within this theoretical framework have mainly focused on the effect of limited types of tasks on the processing of target words (see Kim, 2011for a review). Boggards and Laufer (2004) urge that further research be conducted to investigate the efficiency of various enhancement tasks in vocabulary acquisition. On the other hand, vocabulary retention and recall is a cognitive process which can be immensely affected by the motivational conditions involved in the initial encoding and later processing of unknown words through task performance. Despite the well-recognized role of motivational processes in SL development, little attention has been devoted to possible effects of situated motivation in TBLT context. The concept of 'task motivation' 
(Dornyei, 2001a; Julkunen, 1989, 2001) is a conceptual effort to investigate the contributions of motivational processes to TBLT. One of the practical suggestions regarding the enhancement of task motivation is the concept of 'motivational strategies' cherished by Dornyei (2001b). The current study examined the effect of motivational strategies in conduciveness of tasks aimed at promoting incidental acquisition of $\mathrm{L}_{2}$ vocabulary.

\section{LITERATURE REVIEW}

\section{A. Incidental Vocabulary Acquisition in TBLT Context}

One of the influential positions in offering a breakthrough to the challenge of $\mathrm{L}_{2}$ vocabulary acquisition was the idea of incidental vocabulary acquisition. Although there have been controversies over what is exactly meant by the term 'incidental' (Gass, 1999), the concept seems to have been refined to the following definition: "Incidental learning is the process of learning something without the intention of doing so. It is also learning one thing while intending to learn another" (Brown, Waring \& Donkaewbua, 2008: p 136).

The majority of studies on incidental vocabulary acquisition in a foreign language during 1980's and 1990's, as is evident in the special issue of Studies in Second Language Acquisition (Vol. 21, issue 2, 1999), have focused on the effect of involving subjects in extensive reading concerning pleasurable reading with guessing meaning from context (e.g. Paribakht \& Wesche, 1999) ; however, some researchers have suggested that extensive reading is typically for the purpose of enhancing the knowledge and memory of partially-known words rather than focusing on building new vocabulary (Nation \& Wang, 1999; Waring \&Takaki, 2003). As Huckin and Coady (1999) contend, reading for meaning does not automatically lead to vocabulary acquisition. They attribute the chance of incidental vocabulary acquisition to such factors as the context surrounding each word, frequency of exposure, attention and noticing as well as task characteristics. In this line of research, some sort of instructional intervention for the purpose of enhancing input processing is suggested (Hulstijn, Hollander \& Greidanus, 1996). Schmitt (2008) suggested combining an intentional learning program with extensive reading to cope with the immensity of $\mathrm{L}_{2}$ vocabulary acquisition.

In recent years, due to the new developments within language teaching research including focus on form movement and task-based language teaching, vocabulary learning researchers have also begun to advocate focused instruction of vocabulary (de la Fuente, 2006; Laufer, 2005). One of the instructional techniques for the elaboration of input through reading was glossing (Rott, 2005; Watanabe, 1997; Xu, 2010). Different forms of glosses - marginal and multiple choices, $\mathrm{L}_{1}$ and $\mathrm{L}_{2}$ - were put into scrutiny. The current study uses within-text $\mathrm{L}_{1}$ translations as the form of glosses to assist the processing of unfamiliar words within the reading-while-listening text since $\mathrm{L}_{1}$ glosses have been proved to be as effective as $\mathrm{L}_{2}$ glosses in contributing to vocabulary acquisition (Xu, 2010). Nevertheless research findings regarding the conduciveness of glosses in vocabulary acquisition is not conclusive. Pulido (2009) has asserted that the mere presence of glosses does not always guarantee the retention of lexical knowledge. To make up for this shortcoming, researchers have regarded the characteristics of TBLT situation.

To begin addressing this issue, a number of researchers have offered explanations of why certain tasks are more effective than others in promoting $\mathrm{L}_{2}$ vocabulary acquisition. The nature of task engagement is one of the most viable candidates in determining task effectiveness (Westhoff, 2004). Thus, the study of mental actions involved in the processing of unknown words seems to be an important new dimension to the study of second language incidental vocabulary acquisition.

Since the time Craik and Lockhart (1972) introduced their insight-provoking idea of levels of processing, the issue of the effect of processing conditions in learners' initial encounter with an unfamiliar word on later retention of those words has been one of the routines within SL vocabulary acquisition research. Despite their succeeding attempts to explain the relationship between type of the word-processing and leaving memory traces of it, they were not very successful in clarifying the vague concept of depth of processing.

Laufer and Hulstijn (2001), inspired by the Noticing Hypothesis and Focus on Form Movement, took an influential step toward operationalizing the concept of depth of processing by introducing Involvement Load Hypothesis and the construct of 'task-induced involvement'. The hypothesis proposed a motivational feature of word processing (need) and two cognitive processing features of form-meaning relations (search and evaluation) as the three determining factors in deep processing induced by different task types. They were the first people to put their hypothesis into empirical assessment (Hulstijn \& Laufer, 2001). Since then various studies have been carried out to investigate the effectiveness of task types with different involvement indices in incidental development of vocabulary in recognition and production (see Kim, 2011 for a review).

These studies were mainly focused on the cognitive aspect of input processing. Studies concerning the motivational aspect of task performance are almost missing in the literature. The current study was designed to contribute to the theory of second language acquisition and its pedagogy by filling in the gap on possible effects of eliciting motivational involvement on task engagement and the way promotion in task engagement will influence incidental acquisition of vocabulary.

\section{B. Task Motivation}

The research field on foreign/second language $\left(\mathrm{L}_{2}\right)$ motivation was founded more than half a century ago by Canadian social psychologists, Gardner and Lambert. The earliest theories of $\mathrm{L}_{2}$ motivation looked for a macro- 
understanding of $\mathrm{L}_{2}$ motivation in the overall social and educational context (e.g., Gardner \& Lambert, 1972). However, with a shift of emphasis which began in the 1990's and was fueled by the 1994 debate that went on in the Modern Language Journal, the 'macro-perspective' was reduced to a 'micro-understanding' of $\mathrm{L}_{2}$ motivation in the immediate learning situation. This new perspective led to the blossoming of research on $\mathrm{L}_{2}$ motivation based on 'situated approach' including the influence of the teacher, classmates, task features and task implementation among others. A key conceptualization building the basis for the situated view of motivation was the distinction made by Tremblay, Goldberg and Gardner (1995) between 'trait motivation' and 'state motivation'. Trait motivation, which corresponds mostly to social-psychological view of motivation, involves stable and lasting tendencies of language learners. State motivation, on the other hand, refers to the transitory and temporary motivational responses of language learners to the learning situation. Concerning tasks as a major variable in the learning situation, the trait motivation is general and independent from the task whereas the state motivation is situation-specific and task-dependent (Julkunen, 1989; 2001).

One of the major developments within the situated approach to $\mathrm{L}_{2}$ motivation was the attempt to relate motivation to situation-specific factors in task-based language teaching classes. Dornyei (2002) reiterated that " $\mathrm{L}_{2}$ motivation can hardly be examined in a more situated manner than within a task based framework" (p. 138). The term task motivation is used when task characteristics are the focus of attention in motivation (Dornyei, 2002). Studies of task motivation in SLA research have also concentrated on features of $\mathrm{L}_{2}$ learning situation in predicting task motivation. Dornyei (2009) conceived of task motivation as a complex issue which involves the interaction of the following four factors:

1. Learner-specific factors (e.g., cognitive, motivational and emotional factors; $\mathrm{L}_{2}$ competence; personality traits)

2. Learning situational factors (e.g., teacher, class size, group compositions and school norms and regulations)

3. Task-related factors (e.g., task content, task structure, expected task outcome and task participants)

4. Other factors (e.g., time-related issues, distractions and disruptions)

Empirical studies targeting such a diversity of factors involved in $\mathrm{L}_{2}$ task motivation are still being looked forward to. Most of the studies carried out so far with a focus on task motivation (Dornyei \& Kormos, 2000; Julkunen, 1989, 2001; Kormos \& Dornyei, 2004; Ma, 2009) have resorted to basic motivational constructs postulated in the SelfDetermination Theory (SDT) by Ryan and Doci (2000). Therefore, most of the questionnaires for tapping task motivation are adaptations from the Intrinsic Motivation Inventory (IMI) developed by proponents of SDT (Agnesia, 2010; Dornyei, 2002; Dornyei \& Tseng, 2009; Kormos \& Dornyei, 2004; Ma, 2009). When shuffling through these studies, the following motivational components stand out:

- Perceived value of the task

- Perceived expectancy of success in performing the task

- Perceived effort spent on performing the task

- Perceived autonomy in choosing to do the task

- Perceived enjoyment and pleasure in completing the task

This study is focused on motivational interventions for the purpose of enhancing task effectiveness in incidental acquisition of $\mathrm{L}_{2}$ vocabulary. The motivational intervention will specifically target learners' perceived value of the task, expectancy of success and their enjoyment as determinant components of task motivation as a result of engagement in a reading-while-listening task. The strategies employed to elicit these aspects of task motivation will be discussed in the next section.

\section{Motivational Strategies}

Due to the dynamic and intricate nature of motivational processes, some sort of motivational support through instructional processes is always necessary so that an optimal situation for learning is ensured. Given the central role of motivational attributes in the learning process, motivational strategies can increase the chances of learning achievement (Cheng \& Dornyei, 2007).

Motivational strategies are defined by Dornyei (2001b) as such:

Motivational strategies are techniques that promote the individual's goal-related behavior. Because human behavior is rather complex, there are many diverse ways of promoting it - in fact, almost any influence a person is exposed to might potentially affect his/her behavior. Motivational strategies refer to those motivational influences that are consciously exerted to achieve some systematic and enduring positive effect. (p. 27)

The most academically-appropriate handling of SL motivational strategies was done by Dornyei (2001b). Most of the motivational strategies proposed by Dornyei (2001b) are meant to be related to the language learners' general motivation in long-term trajectory of second language acquisition. However, it has been substantiated through other studies that there is a close relationship between the situation-specific motivation in $\mathrm{L}_{2}$ classroom and general, trait-like motivation (Dornyei, 2002; Dornyei \& Kormos, 2000). There have been very few studies investigating specific motivational designs in the classroom. But given the nature of TBLT and with due reference to Dornyei's (2003) model of task processing, the motivational strategies suggested by Dornyei (2001b) can be accommodated into task-based framework. Dornyei (2003) proposed a theoretical model of motivational task processing which was later validated by Dornyei and Tseng (2009). According to this model, learners' constant appraisal of the upcoming stimuli determines their action control and choice of certain motivational strategies. The model comprises a dynamic task processing system including three inter-related mechanisms of 'task execution', 'appraisal' and 'action control'. 
Based on the dynamic task processing model, the three motivational phases postulated by process models of motivation (Dornyei, 2001a; Dornyei \& Otto, 1998), i.e., pre-actional, actional and post-actional stages can be matched to the three phases of task activities in $\mathrm{L}_{2}$ classes (Ellis, 2003). The pre-actional stage, which concerns choice issues such as the formation of goals and intentions, corresponds to the pre-task stage from TBLT perspective. Dornyei's (2001b) first set of motivational strategies, i.e., those for generating initial motivation can be matched to the preactional/pre-task phase. For the actional stage corresponding to task implementation stage in TBLT, Dornyei (2001b) proposed the second set of strategies for maintaining and protecting motivation. It must be noted that the relationship between the pre-actional and actional stages of motivation is dynamic rather than linear. The dynamicity of motivational constructs has been stressed more vehemently in recent conceptualizations on $\mathrm{L}_{2}$ motivation (Pawlak, 2012). This study intends to examine the effect of inducing motivational involvement on the possible increase of learners' engagement with an input-oriented listening-while reading task. The pre-task phase of classroom teaching process is taken as an opportunity to promote learners' task-related motivation. To this end, a set of motivational strategies suggested by Dornyei, (2001b) which target several motivational constructs conceivable as situated motivational variables including task attitude, autonomy, competence, effort and enjoyment were selected. The selected strategies have been picked out based on the criterion whether they are applicable to situation specific, state motivation. These strategies have been summarized in table I. The operational details related to motivational strategies appear in the methodology section below.

TABLE I.

MOTIVATIONAL STRATEGIES USED FOR ELICITING TASK MOTIVATION (ADAPTED FROM DORNYEI, 2001B)

\begin{tabular}{l} 
1. Present and administer the task in a motivating way by \\
- Explaining the purpose and utility of the task \\
- Whetting students' appetite about the content of the task \\
- roviding appropriate strategies to carry out the task \\
\hline 2. Increase the learners' expectancy of success in performing the task by making sure that \\
- they receive sufficient preparation and assistance \\
- they know exactly what success in the task involves \\
- there are no serious obstacles to success \\
\hline 3. Make learning stimulating and enjoyable to the learners by increasing the attractiveness of the task through \\
- Making the task content-attractive by adapting it to learners' natural interests or by including novel, intriguing, exotic, \\
humorous, competitive or fantasy elements. \\
- Personalizing learning tasks \\
\hline 4. Use goal-setting methods by \\
- Encouraging learners to select specific short-term goals for themselves \\
\hline 5. Build learners' confidence in their learning abilities by teaching them strategies relevant to task performance \\
such as strategies to facilitate the intake of new material \\
\hline 6. Increase learner motivation by actively promoting learner autonomy
\end{tabular}

\section{METHOD}

\section{A. Research Questions and Hypotheses}

The following two questions were the main focus of the study:

1. What is the effect of motivational strategies applied to the pre-task phase of a reading-while-listening task on short-term and long-term retention and ease of activation of second language vocabulary?

2. Do motivational strategies applied to the pre-task phase of a reading-while-listening task have an identical effect on short-term and long-term acquisition of vocabulary?

To initiate the study, the following two hypotheses were proposed:

1. Motivational strategies applied to the pre-task phase of a reading-while-listening task have an enhancing effect on retention and ease of activation of $\mathrm{L}_{2}$ vocabulary.

2. The enhancing effect of motivational strategies in task-engagement is identical for short-term and long-term acquisition of $\mathrm{L}_{2}$ vocabulary.

The independent variable of the study was motivational strategies applied to TBLT classroom through pre-task intervention. The dependent variable was incidental acquisition of SL vocabulary resulting from engagement with a listening-while-reading task. The incidental vocabulary acquisition was measured at the level of its four subcomponents:

1. Short-term retention of vocabulary as measured with a test of passive vocabulary immediately after the task engagement

2. Short-term ease of activation of vocabulary as measured with a test of active vocabulary immediately after the task engagement

3. Long-term retention of vocabulary as measured with a test of passive vocabulary two weeks after the task engagement

4. Long-term ease of activation of vocabulary as measured with a test of active vocabulary two weeks after the task engagement 


\section{B. Participants}

Two intact classes of junior students of English as a foreign language at the Islamic Azad University, Tabriz Branch participated in the study. To ensure homogeneity of the two groups, a pretest was administered to both classes and those who scored below and above the range of 6-25 were left out of the data analysis. Then the two classes were randomly labeled as control group and motivational involvement group, including 24 and 27 students, respectively.

\section{Materials}

The main task was a reading-while-listening task. The text for the reading-while-listening task was extracted from a popular success book Giant Steps, written and read out by Anthony Robins (Robins, 1997). The 20 target words had been signified by $\mathrm{L}_{1}$ glosses within the text. The reading text was followed by a whole-class discussion of the topic of the text The Vocabulary of Success. The students were asked to use as many arguments and illustrations from the text as possible.

To choose the target words, 40 words from the reading-while-listening text which were conjectured to be less familiar to the students were selected and then put to a survey from the students. The survey asked whether they signified each word as familiar or not. If yes, they were supposed to provide an equivalent or explanation inL $L_{1} .20 \mathrm{words}$ which were checked as unfamiliar were selected for the study.

The pretest included reading and listening comprehension items taken from archive versions of TOEFL iBT as the overall listening and reading skills were assumed to be relevant to task performance.

The post-tests were comprised of a vocabulary retention test and a vocabulary ease of activation test. The retention test was a test of passive vocabulary including 10 four-item multiple choice word translation questions from English to Persian. In order to neutralize the effect of guessing, a 5 th item stating 'I'm not sure' was added to the response options $(r=0.71)$. The ease of activation test included 10 fill-in-the-gap sentence translation items from Persian to English. The English translations of the sentences were provided except for the target words $(r=0.78)$.

\section{Procedure}

This study aimed at investigating the effect of motivational strategies on task effectiveness in incidental acquisition of $\mathrm{L}_{2}$ vocabulary. Both control and experimental groups participated in a text-based task preceded by a pre-task phase and succeeded by a post-task phase. The main task was a reading-while-listening task involving reading a text while listening to the text read out by the author. The target words had been highlighted using within-text $\mathrm{L}_{1}$ glosses. The post task entailed a whole-class discussion of the information presented by the reading-while-listening text. The discussion was stimulated by a set of triggering questions that summarized the main points in the text.

While the main task and the post task were identical for both of the groups, the procedure for the pre-task phase was different for the control group and motivational involvement group. The motivational involvement for the experimental group entailed the operationalization of motivational strategies proposed by Dornyei (2001b). The intended motivational strategies (Table I) were pursued through teacher talk, questioning/answering and video show, all of which was integrated into the pre-task phase of task implementation for the experimental group. First, the teacher presented a ten-minute lecture on the three phases of task, criteria for success in the task, how to improve their performance on the task as well as discussing the importance of vocabulary in daily success (the topic of the text was vocabulary of success). Then a short questioning and answering focusing on students' personal experience went on between the teacher and students. Finally, a video clip made by the researcher containing some fascinating pictures displaying Anthony Robins' career and family life accompanied by an attractive song was shown to the class. The control group was engaged in different kind of activities for the pre-task phase. They read a passage on effective communication and answered 8 comprehension questions that followed. The activity took about twenty minutes. The two tests for measuring short-term retention and ease of activation of target vocabulary were administered immediately after the task completion. The tests for measuring long-term retention and ease of activation were administered two weeks later.

\section{E. Data Analysis and Results}

This empirical study was intended to investigate the effect of motivational involvement in task performance on shortterm and long-term retention and ease of activation of $\mathrm{L}_{2}$ vocabulary. The descriptive statistics (means, standard deviations and number of participants) of measures for the four dependent variables are introduced in table II. 
TABLE II.

DESCRIPTIVE STATISTICS

\begin{tabular}{|ll|c|c|c|}
\hline & \multicolumn{1}{|c|}{ Pre-task Intervention } & Mean & Std. Deviation & N \\
\hline Short-term Retention & Control Group & 2.08 & 1.558 & 24 \\
& Motivational Involvement Group & $\mathbf{3 . 5 2}$ & 1.827 & 27 \\
& Total & 2.84 & 1.837 & 51 \\
\hline Short-term Ease of Activation & Control Group & 1.75 & 1.073 & 24 \\
& Motivational Involvement Group & $\mathbf{2 . 5 6}$ & 1.450 & 27 \\
& Total & 2.18 & 1.337 & 51 \\
\hline Long-term Retention & Control Group & 1.79 & 1.215 & 24 \\
& Motivational Involvement Group & $\mathbf{2 . 2 2}$ & 1.423 & 27 \\
& Total & 2.02 & 1.334 & 51 \\
\hline Long-term Ease of Activation & Control Group & 1.62 & 1.096 & 24 \\
& Motivational Involvement Group & $\mathbf{1 . 9 6}$ & 1.192 & 27 \\
& Total & 1.80 & 1.149 & 51 \\
\hline
\end{tabular}

To determine whether there was any significant difference between the control and motivational involvement groups, a multivariate analysis of variance with pre-test as covariate (MANCOVA) was conducted using the scores on the four dependent measures. The MANCOVA results demonstrated an overall significant difference between the two groups. This means that motivational involvement was effective in enhancing incidental acquisition of vocabulary. In addition to this overall effect, further analyses were administered to scrutinize the four subcomponents of incidental acquisition. These analyses indicated a statistically significant difference between the control and motivational involvement groups in terms of short-term retention and ease of activation of vocabulary. However, the differences for long-term retention and ease of activation scores between the two groups were not significant (TableIII).

TABLE III.

EFFECT OF MOTIVATIONAL STRATEGIES ON SHORT-TERM AND LONG-TERM RETENTION AND EASE OF ACTIVATION

\begin{tabular}{|ll|l|l|l|l|l|l|}
\hline Source & Dependent Variable & df & Mean Square & F & Sig. & $\begin{array}{l}\text { Partial Eta } \\
\text { Squared }\end{array}$ & $\begin{array}{l}\text { Observed } \\
\text { Power }^{\text {b }}\end{array}$ \\
\hline groups & Short-term Retention & 1 & 17.043 & 15.690 & $.000^{*}$ & .246 & .973 \\
& $\begin{array}{l}\text { Short-term Ease of } \\
\text { Activation }\end{array}$ & 1 & 4.799 & 6.102 & $.017 *$ & .113 & .677 \\
& $\begin{array}{l}\text { Long-term Retention } \\
\text { Long-term Ease of }\end{array}$ & 1 & .583 & .945 & .336 & .019 & .159 \\
& Activation & 1 & .456 & .579 & .450 & .012 & .116 \\
\hline
\end{tabular}

The results of data analysis corroborate the first hypothesis that motivational strategies applied to the pre-task phase of task engagement had an enhancing effect on both retention and ease of activation. But this enhancement was not identical for short-term and long-term learning. In fact motivational involvement improved both retention and ease of activation scores in the immediate post-test whereas it did not have any significant effect on the performance upon delayed post-test. Therefore, the second hypothesis predicting identical effects of motivational involvement in shortterm and long-term acquisition of vocabulary is not supported statistically.

\section{Discussion AND CONCLUSION}

Task-based language teaching was primarily proposed for helping learners improve their performance aspects of second language such as fluency. However, later developments within TBLT suggested a means for the acquisition of new linguistic elements, including vocabulary and grammar, through so called 'focused tasks' (Ellis, 2003). But using form-focused tasks to develop vocabulary has not been a common practice in SLA (Laufer, 2005). One possible reason for lack of focused tasks for vocabulary acquisition is related to the traditional distinction made between the incidental/intentional and explicit/implicit processes of vocabulary learning and teaching because incidental and implicit learning imply purely meaning-focused involvement (Hulstijn, 2003).

The current study was an attempt to lay incidental vocabulary acquisition in the context of focused tasks. Glosses were exploited as a means of input enhancement during the reading-while-listening task. $\mathrm{L}_{1}$ glosses within the text were supposed to provide chances of noticing during a meaning-focused activity. According to the Noticing Hypothesis, which is a founding theory of TBLT, the linguistic input must be noticed during a meaningful processing before it is acquired. Noticing linguistic elements of input during task engagement depends, to a large extent, on task characteristics and task conditions which may encompass cognitive, emotional and motivational aspects of task performance. What has received greatest attention in the literature is the cognitive processes involved in task performance (e.g. Rahimpour, Salimi \& Farrokhi, 2012; Robinson, 2001; Skehan, 1998). There is a lack of studies investigating emotional and motivational aspects of task conditions. According to Involvement Load Hypothesis (Laufer \& Hulstijn, 2001), tasks which elicit higher levels of involvement yield better retention of vocabulary. Such an involvement, of course, entails two cognitive elements as well as the motivational element of 'need'. Nevertheless, if placed in a general perspective of 
task engagement, the motivational element of task performance can be expanded to other dimensions of motivation including enjoyment, expectancy of success, effort and perceived value of the task in hand. These aspects of task motivation were operationalized in this study through motivational strategies applied to the pre-task phase of the task. According to Willis and Willis (2007), the pre-task stage in TBLT can have a priming effect on later acquisition. The typical pre-task activities target cognitive processes in order to activate schematic knowledge or alleviate linguistic load in task engagement. This study, however, attempted to promote motivational involvement in task performance through pre-task intervention and examine the possible effects on retention and ease of activation of vocabulary encountered for the first time in a text-based focused task.

The results indicated that the motivational involvement had an enhancing effect on both retention and ease of activation of $\mathrm{L}_{2}$ vocabulary in short-term assessment. This finding confirms the postulation that mental actions involved in task performance are not restricted to cognitive processes as they are commonly highlighted in TBLT (e.g. Robinson, 2001). Motivational engagement with a listening-while-reading task had an enhancing effect on later acquisition of vocabulary introduced through this task. This finding is in line with Craik and Lockhart's Depth of Processing Hypothesis which predicts that conceptual processing of new information will improve memory traces of it. Both cognitive and motivational involvement can be considered as instigators of conceptual and deep processing.

Unlike short-term acquisition, the long-term acquisition of vocabulary was not significantly affected by motivational involvement as there was a considerable decay of retention and ease of activation upon the delayed post-test. Therefore, the enhancing effect of motivational involvement was restricted to immediate post-test, and the effect disappeared very soon. In implementing the pre-task based on motivational strategies, cognitive involvement strategies (e.g., to activate schematic knowledge or linguistic priming) were intentionally avoided so that the distinct effect of motivational involvement is observed in the absence of any cognitive involvement strategies. The results demonstrated that motivational involvement alone, cannot lead to acquisition of vocabulary in the long-run.

This study has some pedagogical implications for the use of focused tasks to promote incidental vocabulary acquisition. Using motivational strategies through pre-task intervention leads to the enhancement of task engagement which, in turn, contributes to acquiring lexical aspects of the linguistic input. However an enduring acquisition is not guaranteed if there is not enough cognitive involvement in task engagement. Further research is required to examine the relative impact of motivational and cognitive involvement on incidental acquisition of vocabulary through focused tasks.

\section{ACKNOWLEDGEMENT}

The study reported here is part of a more general Ph.D. project sponsored by the Department of English at the University of Tabriz.

\section{REFERENCES}

[1] Agnesia, R. H. (2010). Features affecting task motivation in English for academic purposes online learning. Second Language Studies, 29(1), 1-34.

[2] Bogaards, P., \& Laufer, B. (2004). Introduction. In P. Bogaards \& B. Laufer (Eds.), Vocabulary in a second language: Selection, acquisition, and testing (pp. vii-xiv). Amsterdam: Benjamins.

[3] Brown, R., Waring, R. \& Donkaewbua, S. (2008). Incidental vocabulary acquisition from reading, reading-while listening, and listening to stories. Reading in a Foreign Language. 20(2), 136-163.

[4] Cheng, H. F. \& Dornyei, Z. (2007). The use of motivational strategies in language instruction: The case of EFL teaching in Taiwan. Innovation in Language Learning and Teaching, 1(1), 153-174.

[5] Craik, F. I. M. and Lockhart, R. S. (1972). Levels of processing: A framework for memory research. Journal of Verbal Learning and Verbal Behavior, 11, 671-684.

[6] Deci, E. L., \& Ryan, R.M. (2000). The "what" and "why" of goal pursuits: Human needs and the self-determination of behavior. Psychological Inquiry, 11(4), 227-268.

[7] Dornyei, Z. \& Tseng, W. T. (2009). Motivational processing in interactional tasks. In: A. Mackey and C. Polio (Eds). Multiple perspectives on interaction: Second language research in honor of Susan Gass (pp. 117-134). London: Rutledge.

[8] Dornyei, Z. (2001a). Teaching and researching motivation. Harlow, England: Longman.

[9] Dornyei, Z. (2001b). Motivational strategies in the classroom. Cambridge: CUP.

[10] Dornyei, Z. (2002). The motivational basis of language learning tasks. In P. Robinson (Ed.), Individual differences in second language acquisition (pp. 137-158). Amsterdam: John Benjamins.

[11] Dornyei, Z. (2003). Attitudes, orientations, and motivations in language learning: Advances in theory, research, and applications. Language Learning, 53, 3-32.

[12] Dornyei, Z. (2009). The antecedents of task behaviour: A dynamic systems account of task motivation. Proceedings of the Third Biennial Conference on Task-Based Language Teaching. Lancaster University.

[13] Dornyei, Z., \& Kormos, J. (2000). The role of individual and social variables in oral task performance. Language Teaching Research, 4, 275-300.

[14] Dörnyei, Z., \& Ottó, I. (1998). Motivation in action: A process model of motivation. Working Papers in Applied Linguistics, 4, 43-69.

[15] Ellis, R. (2003). Task-based language learning and teaching. Oxford: OUP.

[16] de la Fuente, M. J. (2006). Classroom L2 vocabulary acquisition: Investigating the role of pedagogical tasks and form-focused instruction. Language Teaching Research, 10(3), 263-295. 
[17] Gardner, R. C., \& Lambert, W. (1972). Attitudes and motivation in second-language learning. Rowley, MA: Newbury House.

[18] Gass, S. (1999). Discussion: Incidental vocabulary learning. Studies in Second Language Acquisition, 21, 319-333.

[19] Huckin, T. \& Coady, J. (1999). Incidental vocabulary acquisition in a second language; A review. Studies in Second Language Acquisition, 21, 181-193.

[20] Hulstijn, J. H. (2003). Incidental and intentional learning. In: C. J. Doughty and M. H. Long (Eds). The handbook of second language acquisition (pp. 349-381).Malden, MA: Blackwell.

[21] Hulstijn, J. H. and Laufer, B. (2001). Some empirical evidence for involvement load hypothesis in vocabulary acquisition. Language Learning, 51, 539-558.

[22] Hulstijn, J. H., Hollander, M., \& Greidanus, T. (1996). Incidental vocabulary learning by advanced foreign language students: The influence of marginal glosses, dictionary use, and reoccurrence of unknown words. The Modern Language Journal, 80, $327-339$.

[23] Julkunen, K. (1989). Situation- and task-specific motivation in foreign-language learning and teaching. Joensuu, Finland: University of Joensuu Publications in Education.

[24] Julkunen, K. (2001). Situation- and task-specific motivation in foreign language learning. In Z. Dornyei \& R. Schmidt (Eds.). Motivation and second language acquisition (pp. 28-41). Honolulu, HI: University of Hawaii Press.

[25] Kim, Y. (2011). The Role of Task-Induced Involvement and Learner Proficiency in L2 Vocabulary Acquisition. Language Learning, 61:Suppl. 1, 100-140.

[26] Kormos, J. and Dornyei, Z. (2004). The interaction of linguistic and motivational variables in second language task performance. Zeitschrift fur Interkulturellen Fremd Sprachenu Terricht retrieved online June 16, 2012 from http://www.ualberta.ca/ german/ejournal/kormos2.htm. 9.19.

[27] Laufer, B. \& Hulstijn, J. (2001). Incidental vocabulary acquisition in a second language: the construct of task-induced involvement. Applied Linguistics, 22 (1), 1-26.

[28] Laufer, B. (2005). Focus on form in second language vocabulary learning. EUROSLA Yearbook, 5, 223-250.

[29] Ma, J. H. (2009). Autonomy, competence, and relatedness in L2 students' task motivation: A self-determination theory perspective. Unpublished dissertation at the University of Hawai,,i at Mānoa, Honolulu, HI.

[30] Nation, P. \& Wang, M. (1999). Graded readers and vocabulary. Reading in a Foreign Language, 12, 355-380.

[31] Paribakht, S. \& Wesche, M. (1999). Reading and incidental vocabulary acquisition. Studies in Second Language Acquisition, 21, 195-224.

[32] Pawlak, M. (2012). The dynamic nature of motivation in language learning: A classroom perspective. Studies in Second Language Learning and Teaching, 2(2), 249-278.

[33] Pulido, D. (2009). How involved are American L2 learners of Spanish in lexical input processing tasks during reading? Studies in Second Language Acquisition. 31, 31-58.

[34] Rahimpour, M. (1997). Task condition, task complexity and variation in L2 discourse. Unpublished Ph.D. dissertation, University of Queensland, Australia.

[35] Rahimpour, M., Salimi, A. \& Farrokhi, F. (2012). The effect of intensive and extensive focus on form on EFL learners' written accuracy. Theory and Practice in Language Studies, 2(11), 2277-2283.

[36] Robins, A. (1997). Giant Steps: Small changes to make a big difference. London: Simon and Schuster Ltd.

[37] Robinson, P. (2001). Task complexity, cognitive resources, and syllabus design: a triadic framework for examining task influences on SLA. In P. Robinson (Ed.), Cognition and Second Language Instruction (pp. 287-318). Cambridge: Cambridge University Press.

[38] Rott, S. (2005). Processing glosses: A qualitative exploration of how form-meaning connections are established and strengthened. Reading in a Foreign Language, 17(2), 95-124.

[39] Schmitt, N. (2008). Review article: instructed second language vocabulary learning. Language Teaching Research, 12 (3), 329363.

[40] Skehan, P. (1998). A cognitive approach to language learning. Oxford: Oxford University Press.

[41] Swain, M. (2011). The inseparability of cognition and emotion in second language learning. Language Teaching, 45(4), 1-13. doi:10.1017/S0261444811000486.

[42] Tremblay, P., Goldberg, M., \& Gardner, R. (1995). Trait and state motivation and the acquisition of Hebrew vocabulary. Canadian Journal of Behavioural Science, 27, 356-370.

[43] Waring, R., \& Takaki, M. (2003). At what rate do learners learn and retain new vocabulary from reading a graded reader? Reading in a Foreign Language, 15, 130-163.

[44] Watanabe, Y. (1997). Input, intake, and retention: Effects of increased processing on incidental learning of foreign language vocabulary. Studies in Second Language Acquisition, 19, 287-307.

[45] Westhoff, G. (2004). The art of playing a pinball machine. Characteristics of effective SLA tasks. Babylonia, 12(3), 58-62.

[46] Willis, D. \& Willis, J. (2007). Doing task-based teaching. Oxford: Oxford University Press.

[47] $\mathrm{Xu}, \mathrm{X}$. (2010). The effect of glosses on incidental vocabulary acquisition in reading. Journal of Language Teaching and Research. 1(2), 117-120. 


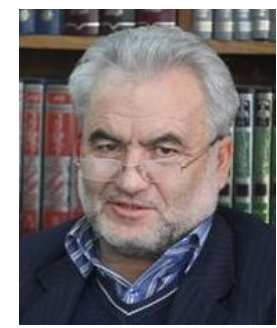

Parviz Ajideh is an associate professor at the department of English, Tabriz University. He holds his Ph.D. in English Language Teaching from the University of Allameh Tabataba'i, Iran. He has published several books and articles in EFL and supervised several M.A. and Ph.D. theses. His special areas of interest are ESP, SL reading and language testing. Dr. Ajideh was the Deputy Minister of Education, Deputy Dean of Faculty, Head of the English Department and Vice Chancellor at Tabriz University. For the time being, he is the Chancellor of Tabriz University.

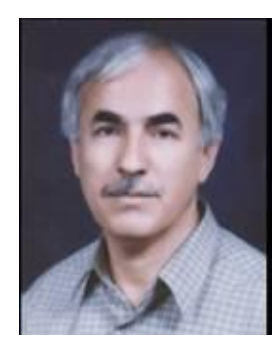

Massoud Rahimpour is an Emeritus Professor at Tabriz University and has been the Honorary Research Consultant at the University of Queensland, Brisbane, Australia. He is holding a M.A in Teaching English from the University of Oklahoma City in the USA and $\mathrm{Ph}$. D in applied linguistics from The University of Queensland in Australia. He lectures in the areas of SLA, syllabus design and TESOL methodology at the University of Tabriz. Dr. Rahimpour has presented and published several books and tens of papers in international conferences and journals. He has also supervised numerous M.A and $\mathrm{Ph}$. D theses. His main areas of interest are task-based language teaching and learning, syllabus design, and research methodology. He is currently teaching at The University of Queensland in Australia.

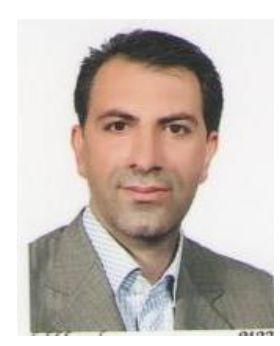

Davoud Amini is a Ph.D. Candidate in English Language Teaching at Tabriz University. Involved with EFL as an instructor and researcher for more than 15 years, he has published the textbook Taking Sides for topicbased conversation classes and presented papers in SLA in international conferences. His academic area of interest includes affectivity in language learning, second language vocabulary acquisition and task-based language teaching.

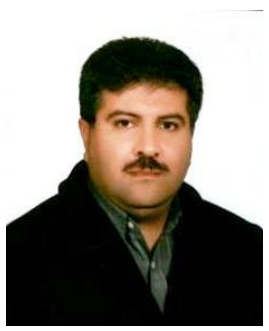

Farahman Farrokhi was born in Iran in 1967. He received his Ph.D. degree in English language teaching from the University of Leeds, England. He is an associate professor at the Department of English at Tabriz University, and currently he is the Dean of the Faculty of Persian Literature and Foreign Languages at Tabriz University. His research interests include classroom discourse analysis, EFL teachers' perceptions of different feedback types, negative and positive evidence in EFL classroom context, language testing, task-based teaching, and syllabus design. 